\title{
Tools for successful proliferation: diverse strategies of nutrient acquisition by a benthic cyanobacterium
}

\author{
H. S. Tee $\mathbb{1}^{1} \cdot$ D. Waite ${ }^{1} \cdot$ L. Payne ${ }^{1} \cdot$ M. Middleditch ${ }^{1} \cdot$ S. Wood ${ }^{2} \cdot$ K. M. Handley $\mathbb{(}^{1}$
}

Received: 22 September 2019 / Revised: 23 April 2020 / Accepted: 1 May 2020 / Published online: 18 May 2020

(c) The Author(s) 2020. This article is published with open access

\begin{abstract}
Freshwater cyanobacterial blooms have increased worldwide, channeling organic carbon into these systems, and threatening animal health through the production of cyanotoxins. Both toxic and nontoxic Microcoleus proliferations usually occur when there are moderate concentrations of dissolved inorganic nitrogen, but when phosphorus is scarce. In order to understand how Microcoleus establishes thick biofilms (or mats) on riverbeds under phosphorus-limiting conditions, we collected Microcoleus-dominated biofilms over a 19-day proliferation event for proteogenomics. A single pair of nitrogen-dependent Microcoleus species were consistently present in relatively high abundance, although each followed a unique metabolic trajectory. Neither possessed anatoxin gene clusters, and only very low concentrations of anatoxins $\left(\sim 2 \mu \mathrm{gg}^{-1}\right)$ were detected, likely originating from rarer Microcoleus species also present. Proteome allocations were dominated by photosynthesizing cyanobacteria and diatoms, and data indicate biomass was actively recycled by Bacteroidetes and Myxococcales. Microcoleus likely acquired nutrients throughout the proliferation event by uptake of nitrate, urea, and inorganic and organic phosphorus. Both species also harbored genes that could be used for inorganic phosphate solubilization with pyrroloquinoline quinone cofactors produced by cohabiting Proteobacteria. Results indicate that Microcoleus are equipped with diverse mechanisms for nitrogen and phosphorus acquisition, enabling them to proliferate and out-compete others in low-phosphorus waters.
\end{abstract}

\section{Introduction}

Over the past few decades, the occurrence of freshwater cyanobacterial blooms has increased worldwide, and is associated with elevated water temperatures and nutrient enrichment [1-3]. The overgrowth and decomposition of cyanobacterial cells drive excessive oxygen consumption in the aquatic environment [4], and some cyanobacteria produce cyanotoxins, which include potent neurotoxins, cytotoxins, hepatotoxins, and endotoxins [5]. All of these toxins represent a health risk to humans and animals. While most

Supplementary information The online version of this article (https:// doi.org/10.1038/s41396-020-0676-5) contains supplementary material, which is available to authorized users.

K. M. Handley

kim.handley@auckland.ac.nz

1 School of Biological Sciences, University of Auckland, Auckland, New Zealand

2 Cawthron Institute, Nelson, New Zealand research has focused on planktonic blooms, benthic mat proliferations of toxin-producing cyanobacteria have been reported with increasing frequency [2, 6-8]. In freshwater systems, these benthic proliferations form visible mats that coat the beds of ponds, lakes, and rivers $[2,6,9,10]$. These mats can be readily ingested by animals, and globally many cases of canine death have been linked to the consumption of benthic mats containing anatoxin-producing cyanobacteria [5, 11, 12], such as Microcoleus autumnalis and favosus (formerly Phormidium autumnale and favosus) [13-16].

Cohesive, flow-tolerant, Microcoleus mats are found in freshwater systems throughout the world, where they commonly form millimeter-thick mats on riverbeds [2, 13, 17, 18]. Microcoleus species that are known to be toxic produce anatoxin-a, its homolog homoanatoxin-a, and their dihydro variants: dihydroanatoxin-a and dihydrohomoanatoxin-a $[13,17]$. Acute exposure to these neurotoxins can cause muscular twitching, loss of coordination, and rapid death from respiratory paralysis [19]. Benthic proliferations of Microcoleus often comprise mixtures of anatoxin-producing and non-anatoxin-producing species/strains [20]. The relative 
abundances of these species/strains are thought to be the main determinant of the level of toxins in a biofilm [20].

Microcoleus species studied to-date lack nitrogenase genes [18, 21], and their proliferations are associated with dissolved inorganic nitrogen (DIN) enrichment [2, 22]. Contrary to the paradigm that influxes of phosphorus drive eutrophication in freshwater [23], Microcoleus readily proliferates in water with low levels of dissolved reactive phosphorus (DRP) [2]. Despite low external phosphorus concentrations, well-established mats are highly enriched in DRP [24]. This internal pool of bioavailable phosphorus is thought to be partly derived from large quantities of fine sediment trapped within the mats. Phosphorus release from this material likely occurs due to high daytime pHs $(>9)$ generated by photosynthesis, and also due to low nighttime dissolved oxygen concentrations $\left(<4 \mathrm{mg} \mathrm{L}^{-1}\right)$, resulting from respiration [24]. In addition, alkaline phosphatase activity in M. autumnalis cultures suggests they have the capability to mineralize organic phosphorus [25]. However, it is unclear whether indirect mechanisms for phosphorus release, such as high $\mathrm{pH}$, are effective at early proliferation stages when biofilms are extremely thin and patchy, or the extent to which Microcoleus mats acquire phosphorus through other routes, such via enzymatic solubilization of inorganic phosphorus or phosphatase-based scavenging of organic phosphorus.

We predicted that to successfully proliferate in low DRP rivers, Microcoleus species are capable of scavenging diverse sources of phosphorus, and some of this phosphorus is sourced through interactions with the wider biofilm community. We sampled Microcoleus mats from a river to capture temporal trends throughout a benthic proliferation event. We then reconstructed bacterial and protist genomes from the biofilm community, and combined these with metaproteomics to determine taxon-specific metabolic profiles.

\section{Materials and methods}

\section{Mat growth and sampling}

At the onset of a late summer proliferation (4th March 2016), cobbles from the Wai-iti River (Nelson, New Zealand) were removed, cleared of incipient growth with sterile sponges, and placed back into the river. Clearing was gentle as seeding from the pre-existing rock surface is important for mat establishment [26]. Five pre-cleared cobbles were collected at each of three time points to capture the first 3,6, and 9 days of growth (Table S1). Additional cobbles that contemporaneously developed biofilms were collected at days 12 and 19. Final sampling on $23^{\text {rd }}$ March 2016 was undertaken prior to forecast heavy rain (Fig. S1), which tends to detach thick Microcoleus mats. The visible biofilms were collected from the rocks with sterile forceps and preserved upon collection in LifeGuard (Qiagen, Hilden, Germany), and stored at $-80^{\circ} \mathrm{C}$.

\section{Physicochemical, nutrient and toxin analysis}

Water temperature and light intensity data were measured every $30 \mathrm{~min}$ (HOBO Pendant ${ }^{\circ}$ UA-002-64, Onset, MA, USA). Daily rainfall and river discharge data were provided by the Tasman District Council, New Zealand. Analysis of nitrite-N, nitrate-N, ammoniacal-N and DRP were carried out using a flow injection analyzer, following a modified APHA 4500 protocol [27]. Anatoxin-a, homoanatoxin-a, dihydroanatoxin-a, and dihydrohomoanatoxin-a were measured using LC-MS/MS [15]. Briefly, biofilm samples were lyophilized and $1 \mathrm{~mL}$ of Milli-Q water with $0.1 \%$ formic acid. Compounds were then separated by liquid chromatography (Waters Acquity UPLC, Waters Corp., MA, USA) on a BEH C18 column $(1.7 \mu \mathrm{m}, 1 \times 50 \mathrm{~mm}$, Waters Corp., MA, USA) and quantified on a Quattro Premier XE triple quadrupole mass spectrometer (Waters-Micromass, Manchester, UK).

\section{Brightfield microscopy}

Biofilms were washed once with $1 \times$ Phosphate Buffer Saline and imaged with a Leica DMR upright microscope using LAS X imaging software (Leica, Germany).

\section{DNA extraction and sequencing}

DNA was extracted from $0.02-0.14 \mathrm{~g}$ of each sample using a MoBio Power Soil DNA Kit (MoBio, CA, USA) and prepared for 16S rRNA amplicon and whole genome shotgun (WGS) sequencing. PCR amplification of $16 \mathrm{~S}$ rRNA genes was performed using modified Earth Microbiome Project primers EMP-16S-515F [28] and EMP-16S806R [29]. Reactions $(50 \mu \mathrm{L})$ were carried out using JumpStart REDTaq Readymix (Sigma-Aldrich, MO, USA) with an initial denaturation step of $95^{\circ} \mathrm{C}$ for $5 \mathrm{~min}, 35$ cycles of $95^{\circ} \mathrm{C}$ for $45 \mathrm{~s}, 50^{\circ} \mathrm{C}$ for $60 \mathrm{~s}, 72^{\circ} \mathrm{C}$ for $90 \mathrm{~s}$, and a final extension step of $72^{\circ} \mathrm{C}$ for 10 mins. The resulting amplicons were purified with Agencourt AMPure XP magnetic beads (Beckman Coulter, CA, USA). Library preparation and $2 \times 250 \mathrm{bp}$ sequencing was performed using the Illumina MiSeq platform with V2 chemistry at Auckland Genomics (University of Auckland, NZ). For WGS sequencing, a minimum of $250 \mathrm{ng}$ of DNA was used. TruSeq DNA nano libraries were prepared to create $550 \mathrm{bp}$ fragments for $2 \times 250 \mathrm{bp}$ sequencing using the Illumina HiSeq 2500 platform with V2 chemistry at the Otago Genomics Facility (University of Otago, NZ). 


\section{Amplicon analysis}

Raw sequences were merged using USEARCH 9.0 -fastq_mergepairs [30] and filtered using sickle [31] with a minimum Phred score of 30 . Sequences were clustered based on a similarity threshold of $\geq 99.9 \%$ into 913 operational taxonomic units (OTUs) using the UCLUST pipeline [32]. OTUs were classified using the USEARCH 9.0 global alignment algorithm with the SILVA SSU Ref NR 99132 [33]. Non-prokaryotic sequences were removed and sequences were rarefied to 2870 using QIIME2 2019.4 [34] leaving 643 OTUs. The Shannon-Wiener index from the BiodiversityR [35] package in $\mathrm{R}$ version 3.5.1 [36] was used to measure bacterial alpha diversity. Nonmetric multidimensional scaling (NMDS) ordinations were plotted based on Bray-Curtis dissimilarities, environmental variables were fitted and $p$ values were generated using the vegan package metaMDS and envfit function [37] with $\mathrm{R}$ version 3.5.1 [36].

\section{Small subunit (SSU) rRNA gene reconstruction and genome assembly}

WGS reads were trimmed using sickle [31] with a minimum Phred score of 30, generating 285 million paired-end reads. Full length 16S rRNA sequences were reconstructed from the combined dataset over 50 iterations using EMIRGE [38] with the SILVA SSU Ref NR 99132 database, and a clustering threshold of $100 \%$, resulting in 201 sequences. For genome assembly, trimmed reads from the same timepoints were coassembled using metaSPAdes [39] with $k$-mer values 41, 61, 81, 101, 127.

\section{Genome binning and annotation}

The 152799 assembled scaffolds ( $\geq 2 \mathrm{~kb}$ in length) were binned using MetaBAT [40], CONCOCT [41] and MaxBin 2.0 [42]. The highest quality prokaryotic bins from each assembly were selected using DASTool [43]. Bins occurring at more than one timepoint were dereplicated using dRep with default parameters, such that bins sharing $\geq 99 \%$ average nucleotide identity (ANI) were dereplicated [44]. Eukaryotic bins were identified according to methods described in Supplementary Materials. The final set of dereplicated prokaryotic and eukaryotic bins was validated using VizBin [45] by calculating tetranucleotide frequencies with the Barnes-Hut stochastic neighbor embedding algorithm. Eighty-two bins were recovered (Table S2), including a combined bin of diatom genomes and 81 prokaryote bins (CheckM completeness $>75 \%$ ). Of these, 45 were nearcomplete (CheckM completeness >95\%) [46]. Genome coverage was determined by mapping reads to bins using Bowtie version 1.2.0 [47], allowing $\leq 3$ mismatch. Open
Reading Frames were predicted and protein sequences predicted using Prodigal [48]. Genes were annotated by searching against UniProt [49], UniRef100 [50], and KEGG Orthologous groups [51] databases using USEARCH 9.0 [30] with an e-value cutoff of 0.001 and a minimum of 50\% identity required. Sequences were also searched against TIGRFAMs [52] and Pfam [53] using HMMER3 [54] with an e-value cutoff of 0.001 , and only hits with the lowest evalue were retained. Taxonomy was assigned using the Genome Taxonomy Database Toolkit (GTDB-TK) v1.3 with release r86 [55].

\section{Growth rates}

Genome replication rates were determined for metagenomeassembled genomes (MAGs) with coverage $\geq 5$, completeness $\geq 75 \%$, and $\leq 175$ scaffolds per Mbp of sequence [56]. Read mapping files were used to calculate the index of replication using iRep default parameters and without GC correction [56]. These MAGs were also used to estimate minimum generation times using growthpred [57] with parameters "-b -c 0 -r -T $20-S$ ". The predicted minimum generation time in this study was calculated based on the organisms synonymous codon usage bias from a set of normally highly expressed genes (mainly rRNA, tRNA) and their growth temperature [57].

\section{Cyanobacteria phylogeny}

EMIRGE-reconstructed cyanobacterial 16S rRNA gene sequences were aligned to the SILVA 132 database [38] using SINA (http://www.arb-silva.de/aligner). Poorly aligned sequences were filtered using MOTHUR [58]. A tree was computed with RAxML using the maximum likelihood method with a GTRGAMMA model and 100 bootstraps [59]. A set of 88 core marker protein sequences were identified, concatenated and aligned using GTDB-tk [55] from cyanobacterial MAGs and closely related genomes from the NCBI Genome database [60] (Table S3). The phylogenetic tree was inferred using RAxML [59] with the PROTGAMMAAUTO model and 100 bootstraps. Trees were annotated and visualized using iTOL [61].

\section{Protein extraction and detection}

Biofilms were freeze-dried and suspended in $100 \mu \mathrm{L}$ of lysis buffer (7 M Urea; $2 \mathrm{M}$ Thiourea; $10 \mathrm{mM}$ DTT; $50 \mathrm{mM}$ Ammonium Bicarbonate, $\mathrm{pH}$ 8.0) per $1 \mathrm{mg}$ dry weight of sample. The solution was homogenized through sonication on ice. Protein concentrations were determined using the EZQ fluorescent protein assay (Invitrogen, CA, USA). Aliquots containing $100 \mu \mathrm{g}$ of protein were adjusted to $100 \mu \mathrm{L}$ with lysis buffer, and proteins were reduced by 
a)

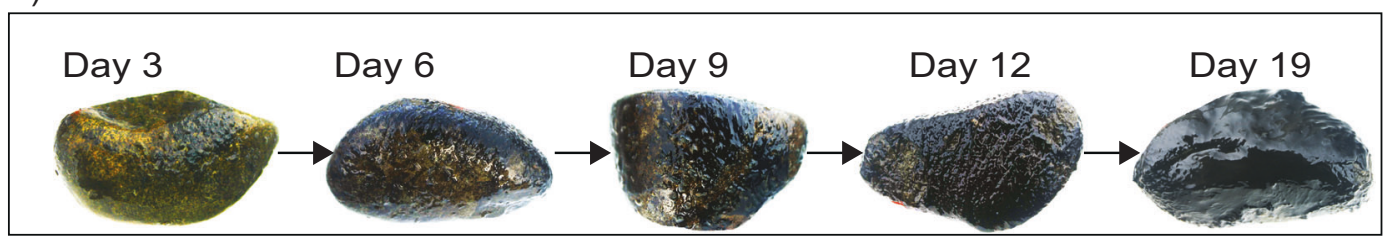

b)
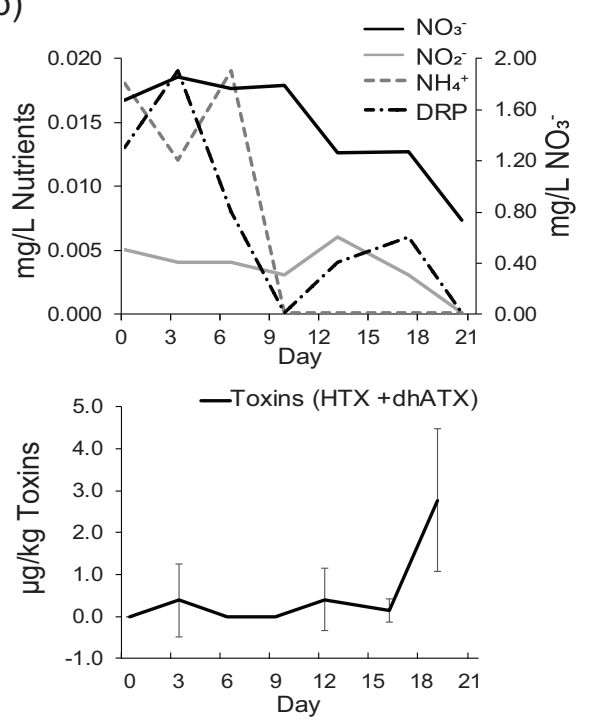

Fig. 1 Images showing Microcoleus mat development, and plots showing changes in nutrients, toxins and mat communities over the 19-day proliferation event. a Photographs of biofilm-coated cobbles collected across five timepoints from day 3 to day 19, showing increasing biofilm cover. Biofilms are dark green in color, and the cobble surfaces are yellow. b Water column nutrient and biofilm toxin concentrations throughout the sampling period. Toxins were measured across six timepoints with four to eight replicates per time point. Day 0 indicates the start of the experiment (4th March 2016). Error bars = standard errors of means. Abbreviations: Nitrate $\left(\mathrm{NO}_{3}{ }^{-}\right)$, Nitrite $\left(\mathrm{NO}_{2}^{-}\right)$,

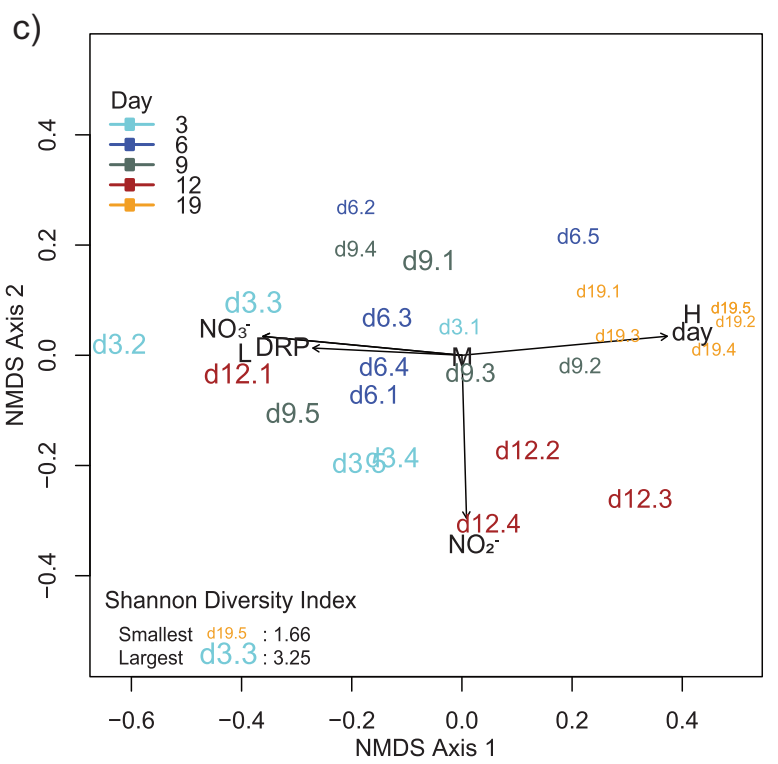

Ammonium $\left(\mathrm{NH}_{4}^{+}\right)$, Dissolved reactive phosphorus (DRP), Anatoxin-a (ATX), dihydro-anatoxin-a (dhATX). c NMDS ordination of amplicon data based on Bray-Curtis dissimilarities. Samples are labeled according to the day of collection with replicate number and the font size represented the Shannon diversity index. The final stress value is 0.14 and the vector indicates fitted environmental parameters significantly correlated to NMDS coordinates $(p<0.05$, permutations $=999)$. Letters in black font indicate categorical vectors for Microcoleus relative abundance: low (L, $0-33 \%)$, medium (M, 33-67\%), and high (H, 67-100\%). incubating at $56^{\circ} \mathrm{C}$ for $1 \mathrm{~h}$. Proteins were alkylated by adding iodoacetamide (final concentration $50 \mathrm{mM}$ ) and incubating in the dark for $30 \mathrm{~min}$ at room temperature. Reactions were quenched by addition of DTT (final concentration $20 \mathrm{mM}$ ). Reduced and alkylated proteins were diluted in 9 volumes of $50 \mathrm{mM}$ Ammonium Bicarbonate, $\mathrm{pH} 8.0$, and $3 \mu \mathrm{g}$ of trypsin was added before samples were digested overnight at $37^{\circ} \mathrm{C}$. Digested proteins were acidified and desalted using HLB columns (Waters Corp, MA, USA) and eluted peptides dried in a Savant Speedvac concentrator (Thermo Fisher Scientific, MA, USA). Peptides were resuspended in $0.5 \mathrm{M}$ triethylammonium bicarbonate (TEAB). Aliquots were taken from a representative subset of samples to create a reference pool for normalization of iTRAQ signals across different runs before samples and the reference pool were labeled with iTRAQ 8plex isobaric tags (Sciex, MA, USA). Labeled samples were pooled and desalted on an HLB column, and analyzed on a TripleTOF 6600 Quadrupole-Time-of-Flight mass spectrometer (Sciex) coupled to an Eksigent NanoLC 400 UHPLC system, controlled using Analyst TF 1.7 software (Sciex) (see Supplementary Materials for run parameters).

\section{Metaproteome analysis}

Peptides were identified using ProteinPilot v5.0 software (Sciex, MA, USA) and predicted protein sequences from the dereplicated set of MAGs. Search parameters were: Sample Type, iTRAQ 8-plex (Peptide Labelled); Search Effort, Thorough; Cys Alkylation, Iodoacetamide; Digestion, Trypsin. A total of 671 proteins were confidently identified and quantified based on the following criteria: (i) local False Discovery Rate $<5 \%$, (ii) total unused score $>1.3$ $(95 \% \mathrm{CI})$, and (iii) proteins were identified in at least two 


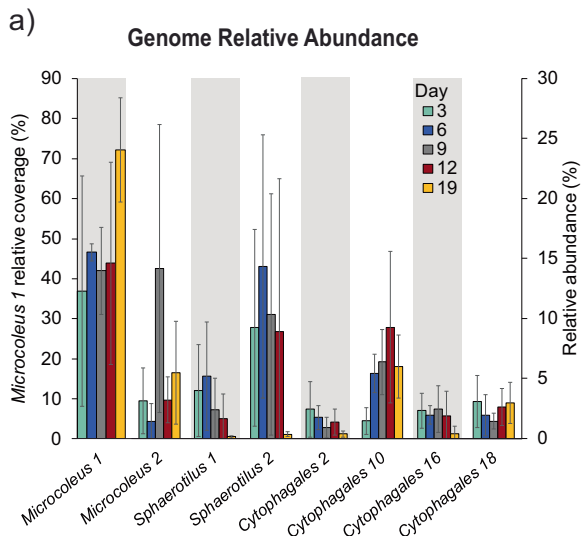

b)

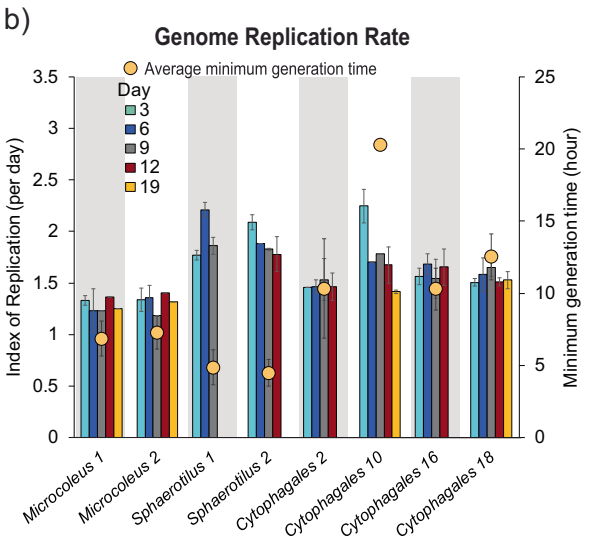

C) Microcoleus Replication Rate and Average Normalized Protein Expression

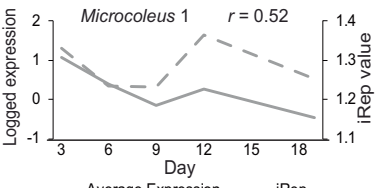

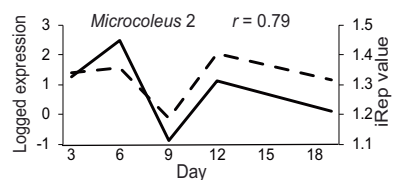

—Average Expression - -iRep

Fig. 2 Plots showing genome coverage, predicted growth rates, and Microcoleus protein expression across five timepoints. a Average relative abundances of the eight dominant MAGs. Microcoleus 1 genome abundance is on a separate y-axis (left) due to higher abundance. Coverage values shown are relative to all the MAGs recovered in the dataset, and for the eight dominant MAGs sum to $62.51 \%$ at day $3,78.61 \%$ at day $6,80.02 \%$ at day $9,72.80 \%$ at day 12 , and $87.81 \%$ at day 19. Error bars = standard errors of means. b Barplot showing predicted replication rates for the same eight MAGs determined using iRep. Yellow circles indicate the average minimum generation time for each MAG determined using growthpred based on codon usage bias. c Close relationship between Microcoleus replication rate and per genome average log-transformed protein expression. The Pearson's correlation coefficient $(r)$ values are indicated. out of three biological replicates. The geometric mean and standard deviation were calculated for replicates. To account for changes in taxa relative abundances, proteins were also normalized to genome coverage. Log fold-change was calculated by subtracting the initial log-transformed value from the final $\log$-transformed value i.e., $\log$ foldchange $=\log _{10}($ final $)-\log _{10}($ initial $)=\log _{10}($ final/initial $)$.

Heatmaps were plotted using gplots [62] in R version 3.5.1 with row-wise scaling for comparison of log-transformed protein expression across timepoints.

\section{Database submissions}

All sequence data from this study have been deposited with NCBI under bioproject PRJNA555798. Peptide and protein summary files were exported to the PRoteomics IDEntifications database under the identifier PXD015625.

\section{Results and discussion}

\section{Microcoleus growth conditions}

During the cyanobacterial proliferation, biofilm thickness and coverage visibly increased from thin and patchy to thick and complete coverage of the upper surfaces of submerged cobbles (Fig. 1a). Temperatures ranged from 14.6 to $23.3{ }^{\circ} \mathrm{C}$, and biofilms received $12-14 \mathrm{~h}$ of daylight per day (Fig. S1). The river discharge was fairly stable $\left(0.4 \mathrm{~m}^{3} \mathrm{~s}^{-1}\right.$ to $\left.0.9 \mathrm{~m}^{3} \mathrm{~s}^{-1}\right)$ throughout the sampling period, which has been shown to be optimal for Microcoleus proliferations [22]. Consistent with previous findings [15], the initial proliferation stage coincided with elevated DIN and low DRP concentrations, both of which decreased over the sampling period (Fig. 1b, c). The nitrate concentration at the start of the experiment was $1.67 \mathrm{mg} \mathrm{L}^{-1}$, and decreased over 2-fold throughout the study period (Fig. 1b).

\section{Microcoleus proliferation}

Amplicon and genome relative abundance data revealed a gradual temporal shift in bacterial community structure (no archaea were detected), and a decrease in microbial community alpha diversity throughout the sampling period (Fig. 1c, a; Tables S2 and S4). This shift was largely driven by increases in the relative abundance of Microcoleus, which already dominated early day 3 biofilms, but also continued to increase throughout the bloom (increasing from $40 \%$ to $78 \%$ of the community) [63]. Biofilms were persistently colonized by two abundant Microcoleus species (Microcoleus 1 and 2). On average, Microcoleus 1 was 8.6 times more abundant. Environmental selection for these species was evidently strong, and conditions were uniform enough to limit niches available to other mat-forming species [64], including anatoxin-producing species or strains. The coexisting Microcoleus pair grew asynchronously throughout the study period, as reflected by their relative abundance profiles (Fig. 2a), and each displayed distinct temporal protein expression patterns, which were closely mirrored by predicted replication rates (Fig. 2b, c). This observation is in line with the reported coupling of photoautotroph growth and protein expression [65]. Despite the temporal variations in predicted growth rates and the large difference in abundance between Microcoleus 1 and 2, the 


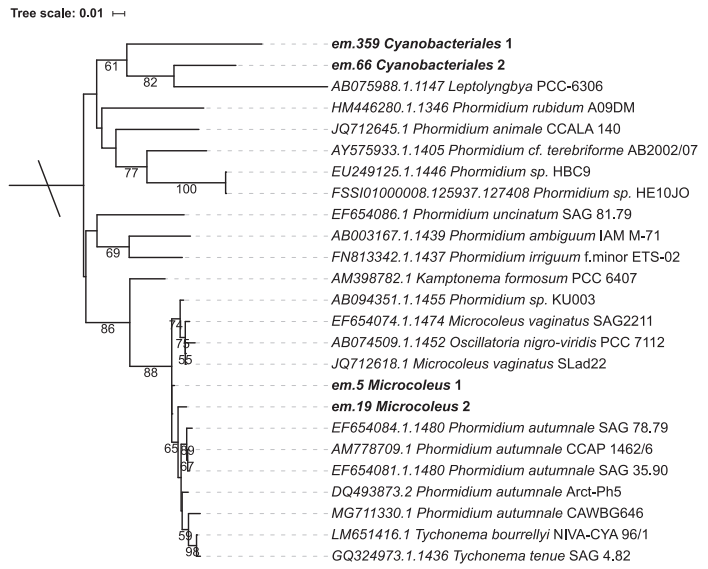

Fig. 3 Maximum likelihood trees showing the phylogenetic relationship between biofilm cyanobacteria and other cyanobacteria. a Phylogenetic tree of cyanobacterial full-length 16S rRNA genes. EMIRGE-reconstructed 16S rRNA genes from this study are indicated in bold. The tree is rooted to Escherichia coli (A14565.1). b Tree

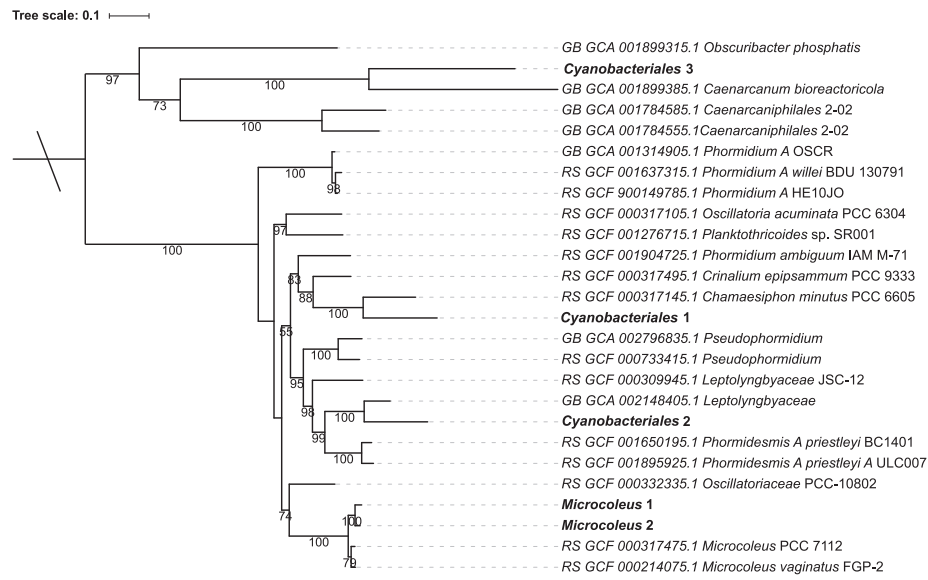

based on 88 concatenated protein markers genes. The five biofilm cyanobacterial genomes are indicated in bold. The tree is rooted to GTDB Gammaproteobacteria UBA1515 (GCA_002323935.1). Scale bars represent number of substitutions per site. Bootstrap values over $50 \%$ are shown. a)

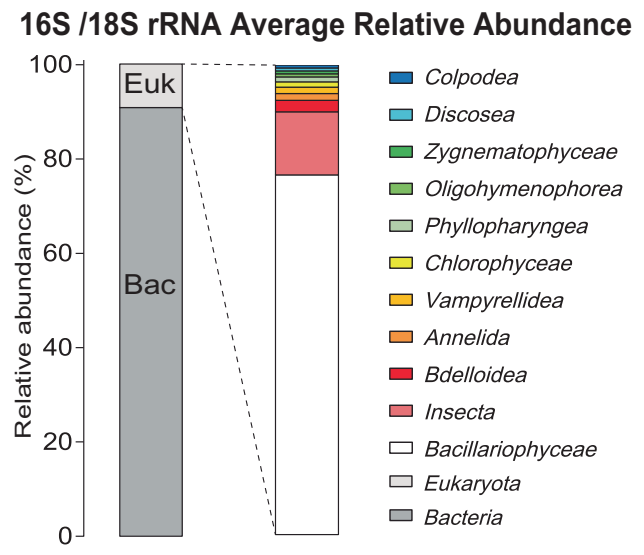

C) Tree scale: $0.1 \mathrm{H}$

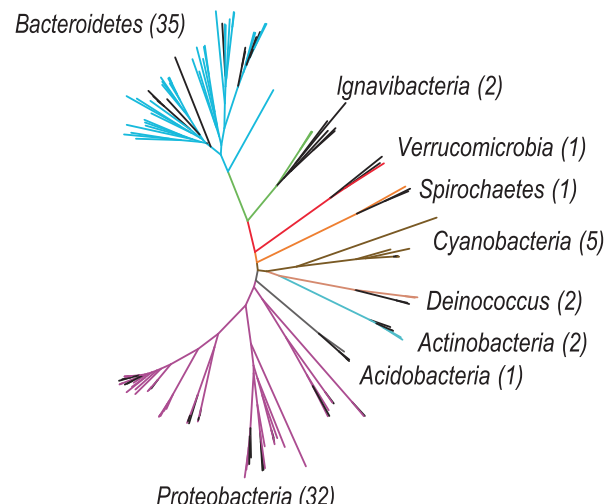

Proteobacteria (32) b)

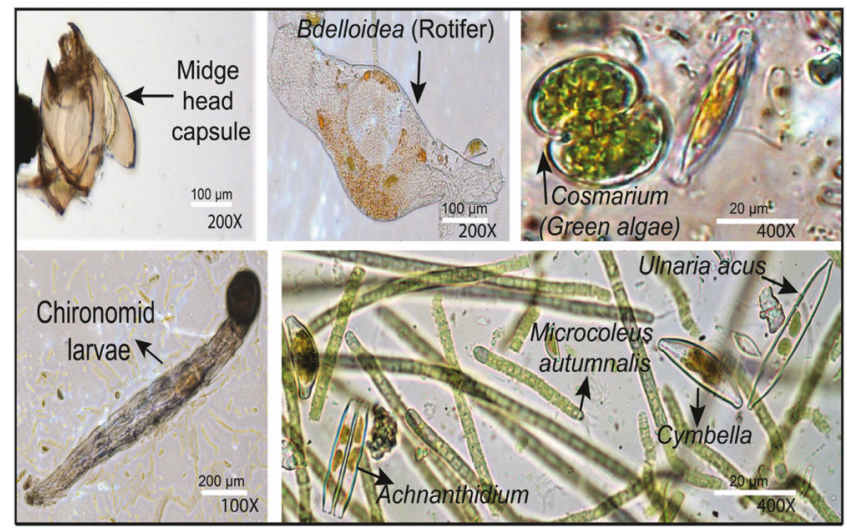

d) Genome Relative Abundance of Top 20 Orders

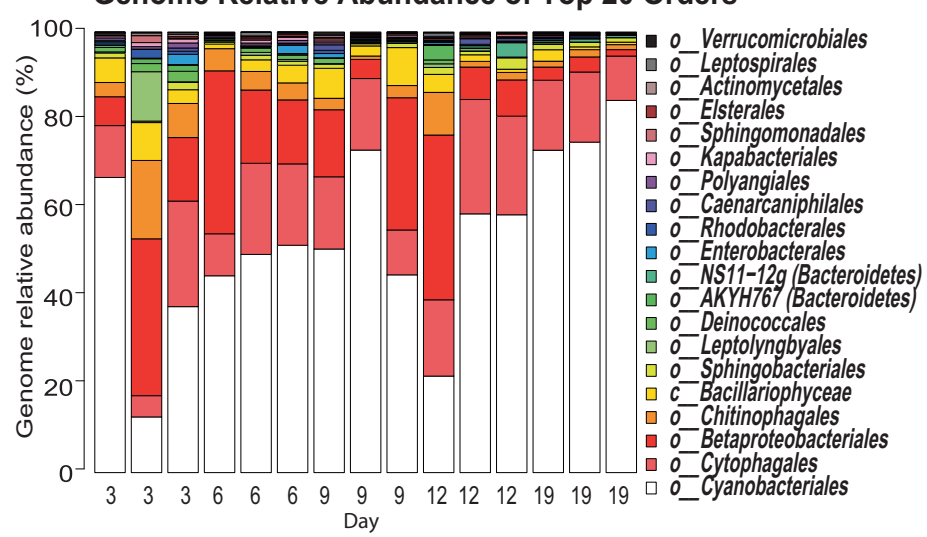

larvae and rotifers). c Unrooted maximum likelihood tree of all 81 prokaryotic MAGs. Black lines indicate references from GTDB, and other tip colors indicate phyla-level clades. d Bar chart showing temporal changes in the relative genome coverage of the top 20 MAGs clustered by order level.
Fig. 4 Community composition of Microcoleus-dominated mats. a Taxa abundances in the combined dataset based on EMIRGEreconstructed 16S and 18S rRNA gene sequences. Bac Bacteria, Euk Eukaryota. b Microscopy images of Microcoleus, eukaryotic phototrophs (diatoms and Cosmarium), and biofilm grazers (chironomid 
average index of replication was near identical for both (iRep index $1.3 \pm 0.1 s$ ). Although the Microcoleus replication rates were modest relative to other major biofilm taxa, their predicted minimum generation times were relatively low $(6.86 \mathrm{~h} \pm 1.21 s$ and $7.28 \mathrm{~h} \pm 1.14 s$, respectively) (Fig. 2b), indicating the capacity for faster replication, particularly by Microcoleus 1 .

\section{Phylogenetic comparison of Microcoleus 1 and 2}

Two assembled full length 16S rRNA genes, and 88 concatenated marker gene protein sequences, from Microcoleus 1 and 2 formed highly conserved clades with Microcoleus species (Fig. 3, details in Supplementary Results). The 16S rRNA gene sequence similarity between the Microcoleus MAGs was $98.9 \%$ (Table S5), which is at the species threshold of 98.7-99\%, [66]. In contrast, the genomes share only $\sim 91 \%$ ANI over an alignable fraction (AF) of $\sim 88 \%$ genes shared (Fig. S2; Table S6). Most intraspecies pairs share greater than $96.5 \%$ ANI and $60 \%$ of genes (as the $\mathrm{AF}$ ), and these values have therefore been recommended as minimum thresholds for species discrimination [67]. Based on proximity to the $16 \mathrm{~S}$ rRNA threshold, and a low genome ANI and AF, the two dominant Microcoleus in this study likely represent distinct species.

\section{Anatoxins and associated genes}

While very toxic Microcoleus mats can contain hundreds of milligrams of anatoxins per kilogram [2], we detected only low concentrations ( 0 to $5.8 \mu \mathrm{g} \mathrm{kg}^{-1}$ ) of homoanatoxin-a and dihydroanatoxin-a (Fig. 1b). Toxin occurrence was patchy among replicates until the final time point, when the highest concentration $\left(4.6 \mu \mathrm{g} \mathrm{kg}^{-1}\right)$ was observed. Dihydrohomoanatoxin-a and anatoxin-a were below detection. No genes known to be associated with anatoxin synthesis were present within the metagenomes. Amplicon data indicate that 156 out of 186 cyanobacterial OTUs belonged to Microcoleus sp., and the remaining 30 OTUs were not from any known anatoxin-producers [68], suggesting toxins were produced by one or more of the rare Microcoleus species (Table S4) [18, 22].

\section{Temporal succession of the benthic mat community}

Ribosomal RNA genes assembled from WGS data and microscopy based observations confirm that submerged cobbles were colonized by a mixture of bacteria, diatoms, non-biting midge larvae (chironomid larvae are known to prey on diatoms [69]), and bdelloid rotifers (Fig. 4a, b; Table S7). Although Microcoleus overwhelmingly dominated the biofilms, the recovery of 81 MAGs spanning 9 bacterial phyla highlights the diversity of associated taxa
(Fig. 4c). The most abundant non-mat forming members of the early biofilm community were Betaproteobacteria (particularly Sphaerotilus), followed by other cyanobacteria (Leptolyngbyales and Candidatus Caenarcanum), Bacteroidetes (notably Cytophagales and Chitinophagales), and diatoms (Bacillariophyta) (Fig. 4d and Table S2). Of these, Betaproteobacteria, Bacillariophyta, and mostly especially Bacteroidetes, have been shown to be major constituents of Microcoleus biofilms $[18,63,70]$. However, we found only a few Bacteroidetes (Bacteroidetes 5, Chitinophagales 3, Cytophagales 7 and 10) and Alphaproteobacteria (Rhodobacterales 2 and Rhodoferax 1) were positively correlated with Microcoleus (genome coverage $r>0.5$; Fig. S3). The genome coverage of diatoms and most bacteria were negatively correlated with Microcoleus $(r<-0.5$; Fig. S3), although the predicted growth rates for some bacteria remained stable (i.e., Cytophagales 2, 16 and 18; Fig. 2b). Betaproteobacteria are often found in high abundance in stream biofilms [71], and likely represent a major part of the original, pre-Microcoleus proliferation, riverbed community in this study. While highly abundant in the early biofilms, Betaproteobacteria dropped seven-fold in relative genome coverage over the study period (from $18.7 \% \pm 14.9 \mathrm{~s}$ to $2.6 \% \pm 1.0 \mathrm{~s}$ ) (Table S2), similar to previous observations by Brasell et. al. [63]. The large magnitude of decrease far outstripped the proportional increase in Microcoleus (only a two-fold increase), and betaproteobacterial abundance also decreased relative to other bacteria (Fig. S4). In addition, the replication rate of the most dominant betaproteobacterium declined through time (Fig. 2), suggesting betaproteobacterial growth declined during biofilm development.

\section{Biofilm organic matter degradation}

Diverse taxa in the Proteobacteria, Verrucomicrobiales, Spirochaetes, Deinococcales, and Actinobacteria, were found to harbor genes for cellulose degradation, whereas most Ignavibacteria and Bacteroidetes were equipped with both cellulase and chitinase genes (Table S8). Proteomic data indicate Bacteroidetes (Chitinophagales 5 and 9) were engaged in biofilm-derived organic matter degradation through the expression of hydrolases and asparaginase (Tables S9 and S10). Their expression (following normalization against genome coverage) was higher in mature biofilms, indicating a higher rate of substrate hydrolysis and proteolytic activity as biomass increased. In addition, Myxococcales 1 encoded and expressed degradative enzymes, including proteases and ribonucleases (Tables S8, S9, and S10), and the greatest expression correlated with the peak abundance of Microcoleus 2 on day 12. Myxococcales are known to prey on other microorganisms (including the 


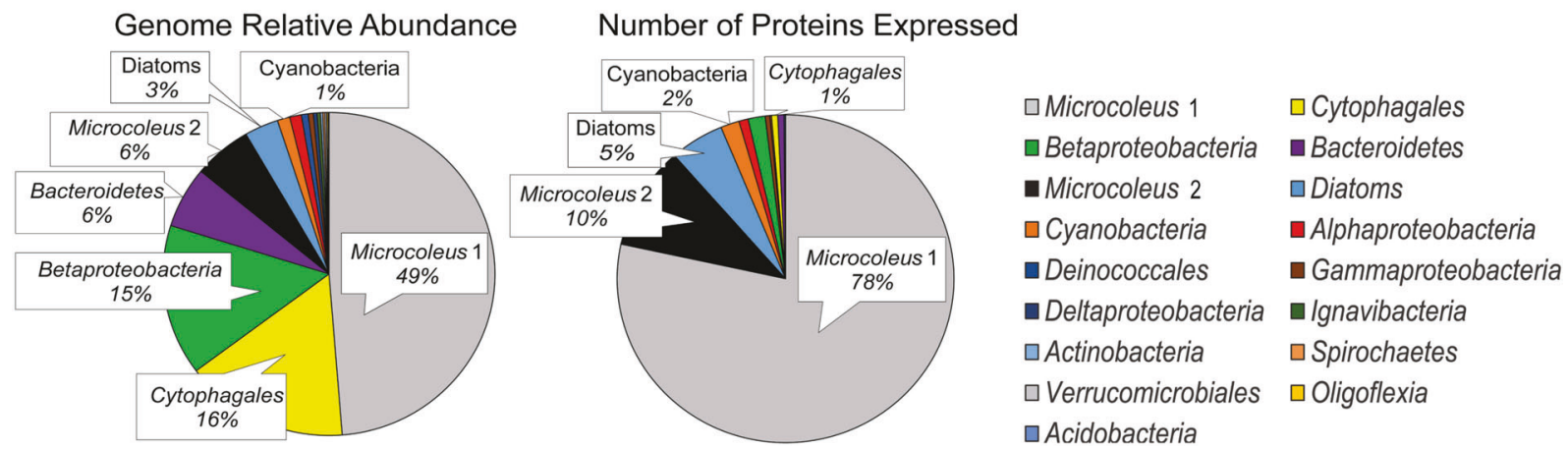

Fig. 5 Comparison between genome relative abundance and number of proteins expressed by the biofilm taxa. The colors denote taxa at a variety of different taxonomic levels that indicate the best classification.

closely related cyanobacterium Phormidium luridus) and control cyanobacterial populations by lysing polysaccharides and other macromolecules in their trichomes and cell walls [72, 73]. It is therefore likely that $M y x$ ococcales 1 targeted Microcoleus for nutrients.

\section{Large protein investment associated with photosynthetic activity}

With the exception of the photoautotrophs $\left(R^{2}=0.96\right)$, we found little correlation between the genome coverage of community members and number of proteins detected (heterotroph $R^{2}=0.20$; Fig. 5 and S5). Almost all proteins detected (95\% based on presence/absence) were from phototrophs (cyanobacteria and diatoms), which represented only $58.9 \%$ of the community based on genome relative abundance (Fig. 5). While genes related to photosynthesis (including photosystems, ATP synthases, and light harvesting complexes) were a relatively minor fraction of the total community gene pool (2.6\%) (Fig. S6), proteins related to photosynthesis were the largest category detected (17.7\%), closely followed by phototroph ribosomal proteins (16.3\%). Prior research has shown that a large fraction of gene transcripts and proteins expressed by phototrophs are related to photosynthesis $[74,75]$. Oxygenic photosynthesis requires a large investment in resources, both in terms of photosynthesis and carbon fixation, which places limitations on photoautotroph growth rates $[76,77]$. Bacteria with relatively slow growth strategies, such as Microcoleus (Fig. 2b), potentially attain disproportionately larger cell volumes and cellular RNA and protein contents [78]. This could explain the large fraction of phototroph proteins detected, along with the relatively large size of trichome-sheathed Microcoleus cells measuring $3 \mu \mathrm{m}$ in diameter (Fig. 4b).

\section{Phototroph diversity and temporal activity}

Oxygenic phototroph contributions to biofilm primary production differed temporally. The majority of photosynthesis and carbon fixation related protein expression from Microcoleus 1 and 2 were higher at later times points (days 12 and 19, respectively), whereas expression from diatoms and other cyanobacteria dropped two-fold through time (Fig. 6 and Table S9). Protein contributions from most, but not all heterotrophs also decreased as biofilms matured. Despite this, when proteins were normalized to changes in taxon-specific genome abundance (i.e., expression per genome), these trends in phototroph expression reversed (Fig. 6 and Table S10). Therefore, although Microcoleus spp. contributed more to overall protein expression and photosynthesis as biomass increased, results suggest a decline in per cell energy capture over time. The decline cannot be attributed to a decrease in Microcoleus growth, as predicted replication rates remained stable - aside from a transient drop in growth rate and overall protein expression associated with high light conditions during day 9 (4.8 times higher than earlier or later; Fig. 2c and S1).

While we only detected activity for oxygenic photosynthesis, we also found genes indicative of anoxygenic photosynthesis (e.g., genes encoding BChl $a$, PufM, and LHC proteins; Table S8) [79] in Acidobacteria and Alphaproteobacteria (Rhodobacterales 1 and 2, and Sphingomonadales 2). No protein expression associated with anoxygenic photosynthesis was detected, although this may reflect peptide detection depth limitations. The acidobacterium was equipped with an inorganic carbon concentrating mechanism (CCM), which enhances inorganic carbon uptake in $\mathrm{CO}_{2}$-limited environments [80]. Although the anoxygenic photosynthetic activity might seem to be negligible, these data indicate that the biofilm community harbored the capacity to harvest light for ATP production using alternative electron donors. For example, Sphingomonadales use thiosulfate rather than $\mathrm{H}_{2} \mathrm{O}$ as electron donor for aerobic anoxygenic photosynthesis [81, 82]. These anoxygenic photoheterotrophs (except Sphingomonadales 2) were proportionally more abundant in early biofilms, and presumably persisted from pre-bloom conditions. 


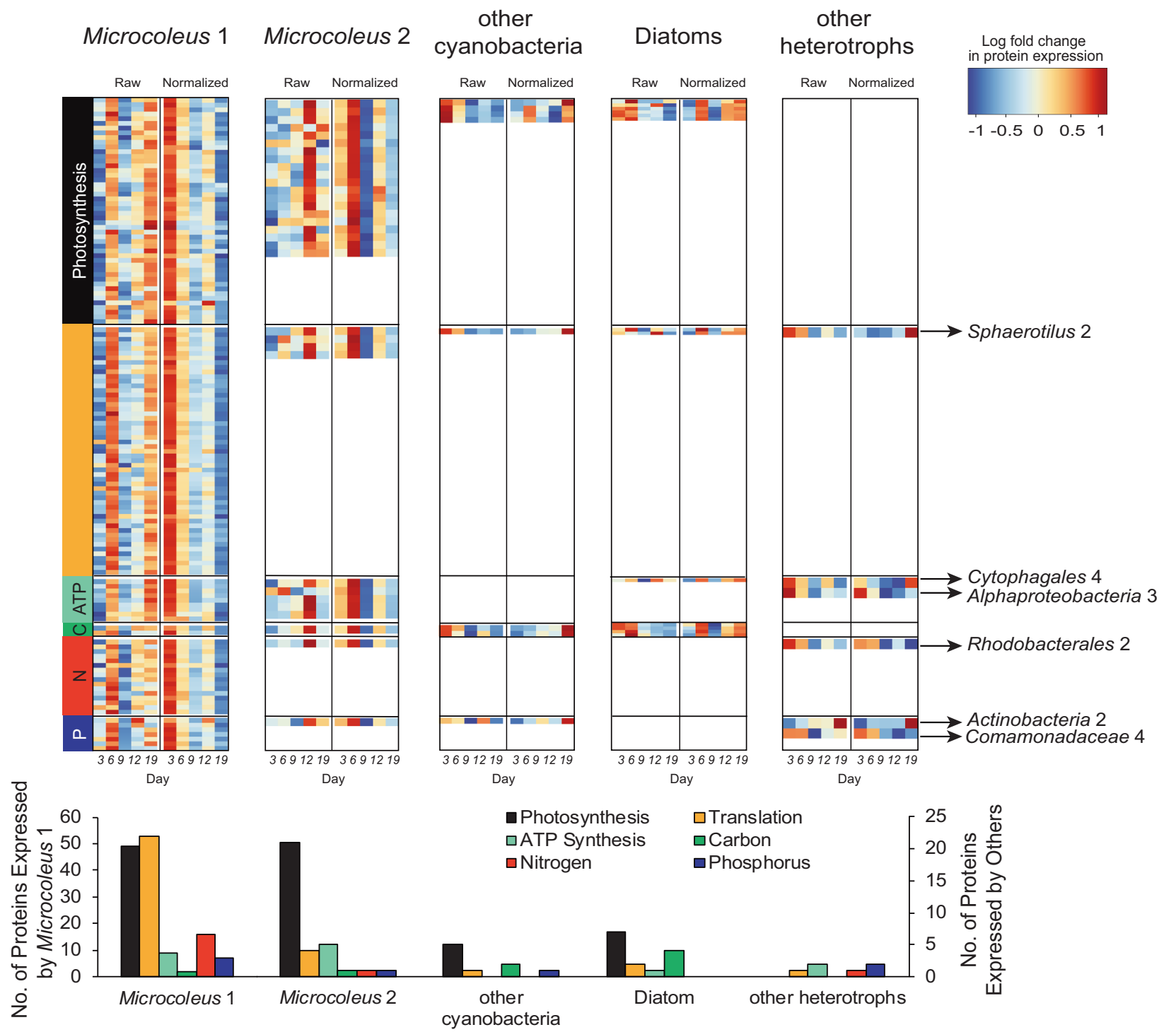

Fig. 6 Protein expression in the biofilm communities. a Heatmaps of log-transformed protein expression data, including both unnormalized protein expression (raw) and protein expression normalized to genome coverage (normalized). Expression data are shown for major metabolic functions: photosynthesis, translation, ATP synthesis, Carbon fixation

\section{Dissolved nitrogen acquisition by Microcoleus and other taxa}

In line with previous studies of Microcoleus in New Zealand and Californian rivers [18, 21], Microcoleus 1 and 2 lack nitrogenase genes (Table S8). Key nitrogenase genes were also absent from the wider biofilm community. Results indicate that Microcoleus 1 dominated biofilm nitrogen acquisition throughout the proliferation by up-taking dissolved nitrate and urea (via NtrBCD and UrtA transporters, respectively, Tables S9 and S10). Although we did not measure urea $\left(\mathrm{NH}_{2} \mathrm{CONH}_{2}\right)$, urea is a problematic agricultural pollutant of water bodies [83]. Both Microcoleus
(C), Nitrogen metabolism (N), and Phosphorus (P). The arrows (right) indicate the heterotrophic taxa with proteins expressed. Protein data are scaled by row. Bar chart below shows the number of proteins expressed by each taxa group based on metabolic functions. Microcoleus 1 protein counts are shown on a separate y-axis (left).

genomes harbored the same capacity for nitrogen acquisition, although protein expression by Microcoleus 2 was below detection for nitrogen metabolism (excluding glutamine synthase). Expression of Microcoleus 1 proteins associated with nitrogen metabolism corresponded strongly with temporal patterns of photosynthesis and carbon assimilation. While these were all more highly expressed during early biofilm formation, data indicate Microcoleus 1 was persistently active in nitrate transport (NtrBCD), assimilatory nitrite reduction (NirBD), urea uptake and degradation (UrtAC and UreABCD), nitrogen regulation and assimilation (P-II protein), and cyanophycin synthesis $(\mathrm{CphA})$ and breakdown $(\mathrm{CphB} \times 2)($ Fig. 6$)$. 


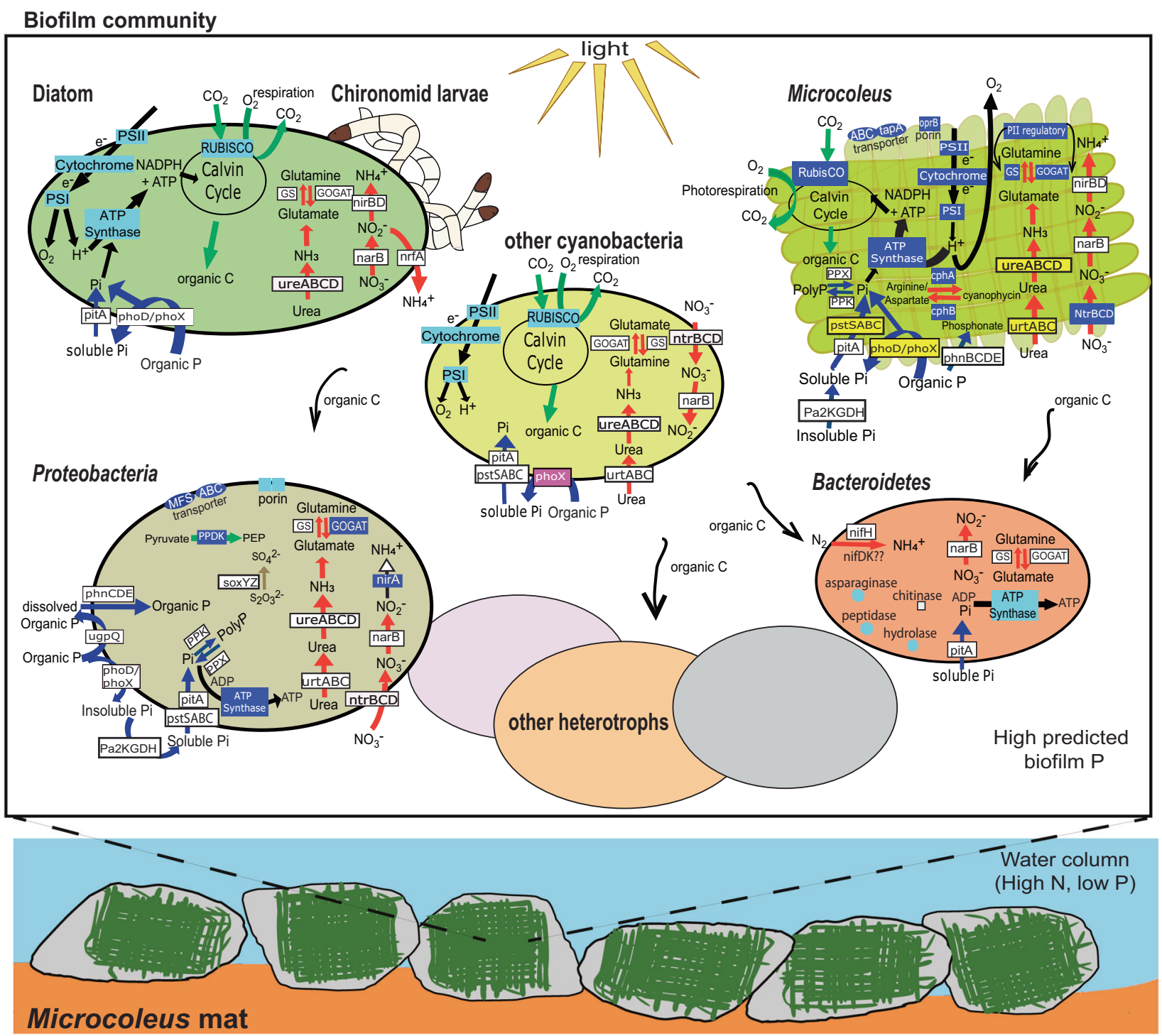

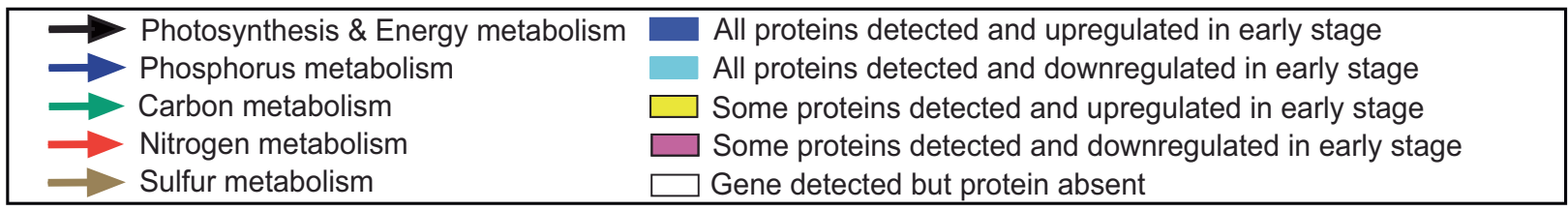

Fig. 7 Schematic illustrating metabolic interactions among biofilm community members using functional genomics and proteomics. Schematic of key genes and proteins expressed within the
Microcoleus-dominated biofilm, with expression up/down regulation shown relative to early/late stage growth of the biofilm. Gene and protein details are documented in Tables S8-S11.
Cyanophycin is common among cyanobacteria, enabling them to store nitrogen in environments subjected to fluctuating nitrogen supply [84]. Prior research has also shown that phosphate starvation promotes cyanophycin accumulation [85]. Both Microcoleus genomes were equipped with two cyanophycin gene clusters, $c p h 1$ and $c p h 2$, each containing cyanophycin synthetase and cyanophycinase genes, similar to Anabaena sp. PCC 7120 [86]. Our proteomics data showed CphA (cyanophycin synthetase) and $\mathrm{CphB}$ (cyanophycinase) expression by Microcoleus 1 throughout biofilm growth (Tables S9 and S10), suggesting active storage and utilization of cyanophycin granules to cope with fluctuations in nutrient supply. Along with proteins for photosynthesis, carbon fixation and nutrient acquisition (Fig. 6), the expression levels of both cyanophycin synthetase and cyanophycinase decreased over time (after normalizing to genome coverage, Fig. 7). Previous studies have primarily focused on cyanophycin in diazotrophs, 
showing that cyanophycin is used by non-heterocystous cyanobacteria when unable to fix nitrogen during the daytime [84, 87], or that cyanophycin is stored at the polar regions of heterocysts to supply nitrogen to vegetative cells [88]. Further research is needed to verify the creation and use of cyanophycin in non-diazotrophic Microcoleus mats.

Various genes involved in nitrogen assimilation from diatoms, other cyanobacteria and diverse bacteria (Proteobacteria, Bacteroidetes, Verrucomicrobia, Ignavibacteria) inhabiting the biofilms were identified, including mechanisms for assimilatory nitrate and nitrite reduction, urea uptake and degradation, and nitrogen regulation (P-II protein and glutamate synthase) (Table S8). Genes for dissimilatory nitrate reduction to ammonium were also present, but only a handful of genes for the denitrification pathway. Given the relatively low protein contribution of heterotrophs in this study, we unsurprisingly detected the expression of only two proteins from this group related to nitrogen metabolism (Fig. 6, Tables S9 and S10).

\section{Phosphate acquisition}

Phosphate is commonly limiting in freshwater systems [89]. Microcoleus biofilm communities were recently shown to harbor diverse mechanisms for phosphate acquisition [18]. Our genomic data agree, showing numerous members of the biofilm community possessed similar genes for low (pitA) and high affinity $(p s t A B C S)$ inorganic phosphate $\left(\mathrm{P}_{\mathrm{i}}\right)$ transporters, organic phosphate mineralization (phosphate monoester metabolism via alkaline phosphatase genes, $p h o A$, phoD, and phoX, and acid phosphatase gene, aphA; glycerol phosphate metabolism via glycerolphosphodiester phosphodiesterase gene, ugpQ), and in/organic phosphate metabolism and transport regulation (phoBRU) (Fig. 7). Further to this, we found that Deinococcales 1 and Microcoleus 1 and 2 harbor an additional mechanism for organic phosphate mineralization via a Class IIIA haloacid dehydrogenase (HAD) superfamily phosphatase (yqeG-like). Our data also indicate the widespread capacity for organic phosphate transport (phosphonate transport, phnBDCE) [90], phosphate storage via genes for polyphosphate synthesis (polyphosphate kinase, $p p k$ ) and degradation (exopolyphosphatase, $p p x$ ) [91, 92], and possible $\mathrm{P}_{\mathrm{i}}$ solubilization via glucose dehydrogenase $(\mathrm{gcd})$ or 2ketoglucose dehydrogenase ( $2 \mathrm{kgdh}$ ). Both Microcoleus 1 and 2 carry almost all of these mechanisms, enabling them to scavenge and utilize various forms of organic phosphate (phnBDCE, phoD, phoX, ugpQ, yqeG-like), solubilize $\mathrm{P}_{\mathrm{i}}$ (2kgd), uptake dissolved $\mathrm{P}_{\mathrm{i}}$ (pitA, pstABCS), and stockpile phosphate ( $p p x, p p k)$.

The putative $P_{i}$ solubilization genes we identified resemble a recently described family of membrane-bound pyrroloquinoline quinone (PQQ) dependent 2-keto-Dglucose (2-ketoglucose) dehydrogenases (2kgdh) [93].
The Pa2KGDH enzyme produces 2-ketogluconic acid from 2-ketoglucose, derived from glucose via an unknown mechanism, and is related to membrane-bound and soluble glucose dehydrogenases, which produce gluconic acid (genes $g c d$ and $g d h B$ ). Production of microbial gluconic acid, and more highly acidic 2-ketogluconic acid, by membrane-bound dehydrogenases can liberate $\mathrm{P}_{\mathrm{i}}$ from calcium phosphates by acidification of the external environment [94]. We found that Microcoleus also possesses oprB genes for carbohydrate-selective porin proteins, which could facilitate the import of glucose, along with some other sugars [95] as fuel for $\mathrm{P}_{\mathrm{i}}$ solubilization, or the import of organic phosphate compounds for direct $\mathrm{P}$ acquisition [96]. Both Microcoleus genomes lack the $p q q$ operon for PQQ synthesis for self-supported PQQdependent $g d h / 2 k g d h$ activity and phosphate solubilization. However, some biofilm Proteobacteria possessed $p q q$ genes (Sphaerotilus 2, Alphaproteobacteria 1, and Myxococcales 1 and 2), and could synthesize PQQ as a public good. Reliance on exogenous PQQ for GDH/ $2 \mathrm{KGDH}$ is a known strategy of some bacteria [97, 98]. While Microcoleus might be able to extract $\mathrm{P}_{\mathrm{i}}$ from particulates with community assistance, proteins expressed by these genes (PQQ or PQQ-dependent GDH/2KGDH) were not detected in this study.

Despite diverse and widespread mechanisms for phosphate metabolism within the biofilm community, most of the measured proteins were expressed by Microcoleus 1 (high affinity phosphate transporters, PstBS and PstS x2 encoded from three distinct operons; organic phosphate phosphatases, PhoX and YqeG-like) (Fig. 6; Tables S9 and S10). Results indicate that Microcoleus 1 actively acquired dissolved $P_{i}$ and metabolized organic phosphate (e.g., phosphate monoesters) (Fig. 7). Coexpression of phosphatases suggests Microcoleus 1 supplemented its exogenous $P_{i}$ intake by hydrolyzing organic phosphate, such as dissolved phosphate monoesters, either periplasmically [99] or extracellularly [100]. In addition, Microcoleus 1 expressed proteins from its two oprB genes (described above), which could have facilitated the uptake of organic phosphate compounds. Overall, results indicate the proliferation was in part sustained by organic phosphate derived from the biofilm community, and Microcoleus did not solely rely on dissolved $\mathrm{P}_{\mathrm{i}}$.

While we predict that DRP was elevated within the sampled biofilms due to $\mathrm{P}_{\mathrm{i}}$ liberation from trapped sediments under the high daytime pHs associated with photosynthetic activity [24], we found that both Microcoleus 1 and 2 expressed the high affinity, low velocity phosphate specific transporter system (Pst), while expression of the higher velocity PitA proteins were not detected. This suggests Microcoleus experienced phosphate limitation. Pst expression increases as phosphate becomes 
increasingly scarce [101], and has been shown to be active when DRP concentrations are as low as $5 \mu \mathrm{g} \mathrm{L}^{-1}$ in marine [102] and $50 \mu \mathrm{g} \mathrm{L}^{-1}$ in lake [103] environments, encompassing the DRP concentrations we measured in the water column $\left(\sim 15 \mu \mathrm{g} \mathrm{L}^{-1}\right.$, Fig. 1). PstS is shown to be repressed at DRP concentrations above $\sim 0.6 \mathrm{mg} \mathrm{L}^{-1}$ [104], which is marginally higher than the elevated DRP concentrations measured by Wood et al. [24] within thick photosynthesizing Microcoleus mats. Duplicate pst clusters in cyanobacteria lacking pitA have been shown to favor distinct $P_{i}$ ranges to cater for starvation and replete conditions [105]. As Microcoleus has higher velocity pitA, the duplicate pst operons of Microcoleus instead might vary in their capacity for $\mathrm{P}_{\mathrm{i}}$ accumulation under limiting conditions [106]. The high-affinity phosphate uptake system also appears to play a critical role in biofilm formation [107].

\section{Conclusions}

The benthic mats were dominated by two stably coexisting Microcoleus species. The majority of proteins detected derived from cyanobacteria and diatoms, which can be accounted for by the large resource investment needed for photosynthesis and carbon fixation. Microcoleus employed diverse strategies for acquiring nutrients throughout mat development. Proteogenomics data indicate that Microcoleus actively sourced nitrogen via urea and nitrate uptake, and suggest that Microcoleus utilized cyanophycin for internal carbon and nitrogen storage. Our data show Microcoleus is equipped with multiple mechanisms for $\mathrm{P}_{\mathrm{i}}$ transport, and both dominant species possessed three mechanisms for organic phosphorus mineralization. Furthermore, Microcoleus actively expressed proteins to simultaneously acquire $\mathrm{P}_{\mathrm{i}}$ and organic phosphorus. Genomic data suggests Microcoleus could potentially carryout $\mathrm{P}_{\mathrm{i}}$ solubilization with the help of collaborative PQQ producers also present in the mats. Results of this study provide insights into how Microcoleus species grow under low $\mathrm{P}_{\mathrm{i}}$ conditions, and suggests that both inorganic and organic phosphorus are important nutrient sources for Microcoleus in benthic biofilms.

Acknowledgements This study was supported by Genomics Aotearoa (project 1806), the University of Auckland's Faculty Research Development Fund, and a Royal Society Te Apārangi Rutherford Discovery Fellowship awarded to KMH. SAW received support for this study from the National Institute of Water and Atmospheric Research under the causes and effects of water quality degradation: eutrophication risk assessment programme. We thank Jonathan Puddick (Cawthron) for toxin analyses. Computational resources were provided by New Zealand eScience Infrastructure, and the University of Auckland's Centre of eResearch.

\section{Compliance with ethical standards}

Conflict of interest The authors declare that they have no conflict of interest.

Publisher's note Springer Nature remains neutral with regard to jurisdictional claims in published maps and institutional affiliations.

Open Access This article is licensed under a Creative Commons Attribution 4.0 International License, which permits use, sharing, adaptation, distribution and reproduction in any medium or format, as long as you give appropriate credit to the original author(s) and the source, provide a link to the Creative Commons license, and indicate if changes were made. The images or other third party material in this article are included in the article's Creative Commons license, unless indicated otherwise in a credit line to the material. If material is not included in the article's Creative Commons license and your intended use is not permitted by statutory regulation or exceeds the permitted use, you will need to obtain permission directly from the copyright holder. To view a copy of this license, visit http://creativecommons. org/licenses/by/4.0/.

\section{References}

1. Huisman J, Codd GA, Paerl HW, Ibelings BW, Verspagen JMH, Visser PM. Cyanobacterial blooms. Nat Rev Microbiol. 2018;16:471-83.

2. McAllister TG, Wood SA, Hawes I. The rise of toxic benthic Phormidium proliferations: A review of their taxonomy, distribution, toxin content and factors regulating prevalence and increased severity. Harmful Algae. 2016;55:282-94.

3. Paerl HW, Huisman J. Climate change: a catalyst for global expansion of harmful cyanobacterial blooms. Environ Microbiol Rep. 2009;1:27-37.

4. Rabalais NN, Díaz RJ, Levin LA, Turner RE, Gilbert D, Zhang J. Dynamics and distribution of natural and human-caused hypoxia. Biogeosciences. 2010;7:585-619.

5. Bláha L, Babica P, Maršálek B. Toxins produced in cyanobacterial water blooms - toxicity and risks. Interdiscip Toxicol. 2009;2:36-41.

6. Bouma-Gregson K, Kudela RM, Power ME Widespread anatoxin-a detection in benthic cyanobacterial mats throughout a river network. PLOS ONE. 2018;13:1-21.

7. Hudon C, De Sève M, Cattaneo A. Increasing occurrence of the benthic filamentous cyanobacterium Lyngbya wollei: a symptom of freshwater ecosystem degradation. Freshw Sci. 2014;33: 606-18.

8. Gaget V, Humpage AR, Huang Q, Monis P, Brookes JD. Benthic cyanobacteria: A source of cylindrospermopsin and microcystin in Australian drinking water reservoirs. Water Res. 2017;124:454-64.

9. Wood SA, Kuhajek JM, Winton M, Phillips NR. Species composition and cyanotoxin production in periphyton mats from three lakes of varying trophic status. FEMS Microbiol Ecol. 2012;79:312-26.

10. Voorhies AA, Eisenlord SD, Marcus DN, Duhaime MB, Biddanda BA, Cavalcoli JD, et al. Ecological and genetic interactions between cyanobacteria and viruses in a low-oxygen mat community inferred through metagenomics and metatranscriptomics: cyanobacteria-virus interactions in a low- $\mathrm{O}_{2}$ mat community. Environ Microbiol. 2016;18:358-71.

11. Puschner B, Hoff B, Tor ER. Diagnosis of anatoxin-a poisoning in dogs from North America. J Vet Diagn Invest. 2008;20:89-92. 
12. Backer LC, Landsberg JH, Miller M, Keel K, Taylor TK. Canine cyanotoxin poisonings in the United States (1920s-2012): review of suspected and confirmed cases from three data sources. Toxins. 2013;5:1597-628.

13. Gugger M, Lenoir S, Berger C, Ledreux A, Druart J-C, Humbert $\mathrm{J}-\mathrm{F}$, et al. First report in a river in France of the benthic cyanobacterium Phormidium favosum producing anatoxin-a associated with dog neurotoxicosis. Toxicon. 2005;45:919-28.

14. Wood SA, Selwood AI, Rueckert A, Holland PT, Milne JR, Smith KF, et al. First report of homoanatoxin-a and associated dog neurotoxicosis in New Zealand. Toxicon. 2007;50:292-301.

15. Wood SA, Puddick J, Fleming R, Heussner AH. Detection of anatoxin-producing Phormidium in a New Zealand farm pond and an associated dog death. NZ J Bot. 2017;55:36-46.

16. Strunecký O, Komárek J, Johansen J, Lukešová A, Elster J. Molecular and morphological criteria for revision of the genus Microcoleus (Oscillatoriales, Cyanobacteria). J Phycol. 2013;49:1167-80.

17. Cadel-Six S, Peyraud-Thomas C, Brient L, Marsac NT, de, Rippka R, Méjean A. Different genotypes of anatoxin-producing cyanobacteria coexist in the Tarn River, France. Appl Environ Microbiol. 2007;73:7605-14.

18. Bouma-Gregson K, Olm MR, Probst AJ, Anantharaman K, Power ME, Banfield JF. Impacts of microbial assemblage and environmental conditions on the distribution of anatoxin-a producing cyanobacteria within a river network. ISME J. 2019;13:1618-34.

19. Fitzgeorge RB, Clark SA, Keevil CW Routes of intoxication. In: Codd GA, Jefferies TM, Keevil CW, Potter E (eds). Detection Methods for Cyanobacterial Toxins. 1994. Woodhead Publishing, pp 69-74.

20. Wood SA, Puddick J. The abundance of toxic genotypes is a key contributor to anatoxin variability in Phormidium-dominated benthic mats. Mar Drugs. 2017;15:307.

21. Heath M, Wood SA, Young RG, Ryan KG. The role of nitrogen and phosphorus in regulating Phormidium sp. (cyanobacteria) growth and anatoxin production. FEMS Microbiol Ecol. 2016;92:fiw021.

22. Wood SA, Atalah J, Wagenhoff A, Brown L, Doehring K, Young RG, et al. Effect of river flow, temperature, and water chemistry on proliferations of the benthic anatoxin-producing cyanobacterium Phormidium. Freshw Sci. 2016;36:63-76.

23. Carpenter SR. Eutrophication of aquatic ecosystems: bistability and soil phosphorus. Proc Natl Acad Sci. 2005;102:10002-5.

24. Wood SA, Depree C, Brown L, McAllister T, Hawes I. Entrapped sediments as a source of phosphorus in epilithic cyanobacterial proliferations in low nutrient rivers. PLoS ONE. 2015;10:e0141063.

25. Kelly LT, Ryan KG, Wood SA. Differential strain response in alkaline phosphatase activity to available phosphorus in Microcoleus autumnalis. Harmful Algae. 2019;89:101664.

26. Atalah J, Rabel H, Thomson-Laing G, Wood SA. Drivers of Phormidium blooms in Southland rivers and the development of a predictive model, Report No. 3196. 2018. Cawthron Institute: Nelson, New Zealand.

27. Rice EW, Baird RB, Eaton AD, Clesceri LS (eds). Standard methods for the examination of water and wastewater, 22nd ed. 2012. American Public Health Association, American Water Works, Water Environment Federation, Washington DC, USA.

28. Hugerth LW, Wefer HA, Lundin S, Jakobsson HE, Lindberg M, Rodin S, et al. DegePrime, a program for degenerate primer design for broad-taxonomic-range PCR in microbial ecology studies. Appl Environ Microbiol. 2014;80:5116-23.

29. Walters W, Hyde ER, Berg-Lyons D, Ackermann G, Humphrey G, Parada A, et al. Improved bacterial 16S rRNA gene (V4 and V4-5) and fungal internal transcribed spacer marker gene primers for microbial community surveys. mSystems. 2016;1: e00009-15.

30. Edgar RC. Search and clustering orders of magnitude faster than BLAST. Bioinformatics. 2010;26:2460-1.

31. Joshi N, Fass J A sliding-window, adaptive, quality-based trimming tool for FastQ files (Version 1.33) [Software]. 2011. https://github.com/najoshi/sickle.

32. Edgar RC. UPARSE: highly accurate OTU sequences from microbial amplicon reads. Nat Methods. 2013;10:996.

33. Quast C, Pruesse E, Yilmaz P, Gerken J, Schweer T, Yarza P, et al. The SILVA ribosomal RNA gene database project: improved data processing and web-based tools. Nucleic Acids Res. 2013;41:D590-6.

34. Bolyen E, Rideout JR, Dillon MR, Bokulich NA, Abnet C, AlGhalith GA, et al. QIIME 2: reproducible, interactive, scalable, and extensible microbiome data science. PeerJ 2018;37:852-7.

35. Kindt R A manual and software for common statistical methods for ecological and biodiversity studies. 2005. World Agroforestry Centre (ICRAF), Nairobi (Kenya).

36. R Core Team. R: a language and environment for statistical computing. 2018. R Foundation for Statistical Computing, Vienna, Austria.

37. Oksanen J, Blanchet FG, Friendly M, Kindt R, Legendre P, McGlinn D, et al. vegan: community ecology package (Version 2.5-6) [Software]. 2019. https://CRAN.R-project.org/package= vegan.

38. Miller CS, Baker BJ, Thomas BC, Singer SW, Banfield JF. EMIRGE: reconstruction of full-length ribosomal genes from microbial community short read sequencing data. Genome Biol. 2011;12:R44.

39. Nurk S, Meleshko D, Korobeynikov A, Pevzner PA. metaSPAdes: a new versatile metagenomic assembler. Genome Res. 2017;27:824-34.

40. Kang DD, Froula J, Egan R, Wang Z. MetaBAT, an efficient tool for accurately reconstructing single genomes from complex microbial communities. PeerJ. 2015;3:e1165.

41. Alneberg J, Bjarnason BS, de Bruijn I, Schirmer M, Quick J, Ijaz UZ, et al. Binning metagenomic contigs by coverage and composition. Nat Methods. 2014;11:1144-6.

42. Wu Y-W, Simmons BA, Singer SW. MaxBin 2.0: an automated binning algorithm to recover genomes from multiple metagenomic datasets. Bioinformatics. 2016;32:605-7.

43. Sieber CMK, Probst AJ, Sharrar A, Thomas BC, Hess M, Tringe $\mathrm{SG}$, et al. Recovery of genomes from metagenomes via a dereplication, aggregation and scoring strategy. Nat Microbiol. 2018;3:836

44. Olm MR, Brown CT, Brooks B, Banfield JF. dRep: a tool for fast and accurate genomic comparisons that enables improved genome recovery from metagenomes through de-replication. ISME J. 2017;11:2864-8.

45. Laczny CC, Sternal T, Plugaru V, Gawron P, Atashpendar A, Margossian HH, et al. VizBin - an application for referenceindependent visualization and human-augmented binning of metagenomic data. Microbiome. 2015;3:1.

46. Parks DH, Imelfort M, Skennerton CT, Hugenholtz P, Tyson GW. CheckM: assessing the quality of microbial genomes recovered from isolates, single cells, and metagenomes. Genome Res. 2015;25:1043-55.

47. Langmead B, Trapnell C, Pop M, Salzberg SL. Ultrafast and memory-efficient alignment of short DNA sequences to the human genome. Genome Biol. 2009;10:R25.

48. Hyatt D, Chen G-L, LoCascio PF, Land ML, Larimer FW, Hauser LJ. Prodigal: prokaryotic gene recognition and translation initiation site identification. BMC Bioinform. 2010;11:119. 
49. Bateman A, Martin MJ, O'Donovan C, Magrane M, Alpi E, Antunes R, et al. UniProt: the universal protein knowledgebase. Nucleic Acids Res. 2017;45:D158-69.

50. Suzek BE, Wang Y, Huang H, McGarvey PB, Wu CH. UniRef clusters: a comprehensive and scalable alternative for improving sequence similarity searches. Bioinformatics. 2015;31:926-32.

51. Kanehisa M, Goto S. KEGG: kyoto encyclopedia of genes and genomes. Nucleic Acids Res. 2000;28:27-30.

52. Haft DH, Selengut JD, White O. The TIGRFAMs database of protein families. Nucleic Acids Res. 2003;31:371-3.

53. Sonnhammer EL, Eddy SR, Birney E, Bateman A, Durbin R. Pfam: multiple sequence alignments and HMM-profiles of protein domains. Nucleic Acids Res. 1998;26:320-2.

54. Eddy SR. Accelerated profile HMM searches. PLoS Comput Biol. 2011;7:e1002195.

55. Parks DH, Chuvochina M, Waite DW, Rinke C, Skarshewski A, Chaumeil P-A, et al. A standardized bacterial taxonomy based on genome phylogeny substantially revises the tree of life. Nat Biotechnol. 2018;36:996-1004.

56. Brown CT, Olm MR, Thomas BC, Banfield JF. Measurement of bacterial replication rates in microbial communities. Nat Biotechnol. 2016;34:1256-63.

57. Vieira-Silva S, Rocha EPC. The systemic imprint of growth and its uses in ecological (meta)genomics. PLoS Genet. 2010;6: e1000808.

58. Schloss PD, Westcott SL, Ryabin T, Hall JR, Hartmann M, Hollister EB, et al. Introducing mothur: open-source, platformindependent, community-supported software for describing and comparing microbial communities. Appl Env Microbiol. 2009;75:7537-41.

59. Stamatakis A. RAxML version 8: a tool for phylogenetic analysis and post-analysis of large phylogenies. Bioinformatics. 2014;30:1312-3.

60. NCBI Resource Coordinators. Database resources of the National Center for Biotechnology Information. Nucleic Acids Res. 2018;46:D8-13.

61. Letunic I, Bork P. Interactive Tree Of Life (iTOL): an online tool for phylogenetic tree display and annotation. Bioinformatics. 2007;23:127-8.

62. Warnes GR, Bolker B, Bonebakker L, Gentleman R, Liaw WHA, Lumley T, et al. gplots: various R programming tools for plotting data (Version 3.0.1) [Software]. 2016. https://CRAN.Rproject.org $/$ package $=$ gplots.

63. Brasell KA, Heath MW, Ryan KG, Wood SA. Successional change in microbial communities of benthic Phormidiumdominated biofilms. Micro Ecol. 2015;69:254-66.

64. Cardinale BJ. Biodiversity improves water quality through niche partitioning. Nature. 2011;472:86-9.

65. Jahn M, Vialas V, Karlsen J, Maddalo G, Edfors F, Forsström B, et al. Growth of cyanobacteria is constrained by the abundance of light and carbon assimilation proteins. Cell Rep. 2018;25:478. e8

66. Stackebrandt E, Ebers J. Taxonomic parameters revisited: tarnished gold standards. Microbiol Today. 2006;33:152-5.

67. Varghese NJ, Mukherjee S, Ivanova N, Konstantinidis KT, Mavrommatis K, Kyrpides NC, et al. Microbial species delineation using whole genome sequences. Nucleic Acids Res. 2015;43:6761-71.

68. Chorus I, Bartram J (eds). Toxic cyanobacteria in water: a guide to their public health consequences, monitoring, and management. 1999. E \& FN Spon, World Health Organization, London; New York.

69. Tarkowska-Kukuryk M. Periphytic algae as food source for grazing chironomids in a shallow phytoplankton-dominated lake. Limnologica. 2013;43:254-4.

70. Echenique-Subiabre I, Zancarini A, Heath MW, Wood SA, Quiblier C, Humbert J-F. Multiple processes acting from local to large geographical scales shape bacterial communities associated with Phormidium (cyanobacteria) biofilms in French and New Zealand rivers. Sci Rep. 2018;8:14416.

71. Battin TJ, Besemer K, Bengtsson MM, Romani AM, Packmann AI. The ecology and biogeochemistry of stream biofilms. Nat Rev Microbiol. 2016;14:251-63.

72. Burnham JC, Collart SA, Daft MJ. Myxococcal predation of the cyanobacterium Phormidium luridum in aqueous environments. Arch Microbiol. 1984;137:220-5.

73. Shilo M. Lysis of blue-green algae by Myxobacter. J Bacteriol. 1970;104:453-61.

74. Park J-J, Lechno-Yossef S, Wolk CP, Vieille C. Cell-specific gene expression in Anabaena variabilis grown phototrophically, mixotrophically, and heterotrophically. BMC Genomics. 2013;14:759.

75. Zavřel T, Faizi M, Loureiro C, Poschmann G, Stühler K, Sinetova $\mathrm{M}$, et al. Quantitative insights into the cyanobacterial cell economy. eLife. 2019;8:e42508.

76. Raven JA, Beardall J, Larkum AWD, Sánchez-Baracaldo P. Interactions of photosynthesis with genome size and function. Philos Trans R Soc B Biol Sci. 2013;368:20120264.

77. Burnap RL. Systems and photosystems: cellular limits of autotrophic productivity in cyanobacteria. Front Bioeng Biotechnol. 2015;3:1.

78. Cox RA. Correlation of the rate of protein synthesis and the third power of the RNA:protein ratio in Escherichia coli and Mycobacterium tuberculosis. Microbiology. 2003;149:729-37.

79. Tang K-H, Tang YJ, Blankenship RE. Carbon metabolic pathways in phototrophic bacteria and their broader evolutionary implications. Front Microbiol. 2011;2:165.

80. Dobrinski KP, Longo DL, Scott KM. The carbon-concentrating mechanism of the hydrothermal vent chemolithoautotroph Thiomicrospira crunogena. J Bacteriol. 2005;187:5761-6.

81. Yurkov VV, Beatty JT. Aerobic anoxygenic phototrophic bacteria. Microbiol Mol Biol Rev. 1998;62:695-724.

82. Imhoff JF, Rahn T, Künzel S, Neulinger SC. Phylogeny of anoxygenic photosynthesis based on sequences of photosynthetic reaction center proteins and a key enzyme in bacteriochlorophyll biosynthesis, the chlorophyllide reductase. Microorganisms. 2019;7:576.

83. Finlay K, Patoine A, Donald DB, Bogard MJ, Leavitt PR. Experimental evidence that pollution with urea can degrade water quality in phosphorus-rich lakes of the Northern Great Plains. Limnol Oceanogr. 2010;55:1213-30.

84. Watzer B, Forchhammer K. Cyanophycin synthesis optimizes nitrogen utilization in the unicellular cyanobacterium Synechocystis sp. PCC 6803. Appl Environ Microbiol. 2018;84: $1-18$.

85. Trautmann A, Watzer B, Wilde A, Forchhammer K, Posten C. Effect of phosphate availability on cyanophycin accumulation in Synechocystis sp. PCC 6803 and the production strain BW86. Algal Res. 2016;20:189-96.

86. Picossi S, Valladares A, Flores E, Herrero A. Nitrogen-regulated genes for the metabolism of cyanophycin, a bacterial nitrogen reserve polymer: expression and mutational analysis of two cyanophycin synthetase and cyanophycinase gene clusters in heterocyst-forming cyanobacterium Anabaena sp. PCC 7120. J Biol Chem. 2004;279:11582-92.

87. Sherman LA, Meunier P, Colon-Lopez MS Diurnal rhythms in metabolism: a day in the life of a unicellular, diazotrophic cyanobacterium. 1998;18.

88. Burnat M, Herrero A, Flores E. Compartmentalized cyanophycin metabolism in the diazotrophic filaments of a heterocyst-forming cyanobacterium. Proc Natl Acad Sci. 2014;111:3823-8.

89. Correll D. Phosphorus: a rate limiting nutrient in surface waters. Poult Sci. 1999;78:674-82. 
90. Stasi R, Neves HI, Spira B. Phosphate uptake by the phosphonate transport system PhnCDE. BMC Microbiol. 2019;19:79.

91. Akiyama M, Crooke E, Kornberg A. The polyphosphate kinase gene of Escherichia coli. Isolation and sequence of the ppk gene and membrane location of the protein. J Biol Chem. 1992;267:22556-61.

92. Akiyama M, Crooke E, Kornberg A. An exopolyphosphatase of Escherichia coli. The enzyme and its ppx gene in a polyphosphate operon. J Biol Chem. 1993;268:633-9.

93. Umezawa K, Takeda K, Ishida T, Sunagawa N, Makabe A, Isobe $\mathrm{K}$, et al. A novel pyrroloquinoline quinone-dependent 2-keto-Dglucose dehydrogenase from Pseudomonas aureofaciens. J Bacteriol. 2015;197:1322-9.

94. Sashidhar B, Podile AR. Mineral phosphate solubilization by rhizosphere bacteria and scope for manipulation of the direct oxidation pathway involving glucose dehydrogenase. J Appl Microbiol. 2010;109:1-12.

95. Wylie JL, Worobec EA. The OprB porin plays a central role in carbohydrate uptake in Pseudomonas aeruginosa. J Bacteriol. 1995;177:3021-6.

96. Reistetter EN, Krumhardt K, Callnan K, Roache-Johnson K, Saunders JK, Moore LR, et al. Effects of phosphorus starvation versus limitation on the marine cyanobacterium Prochlorococcus MED4 II: gene expression: Molecular response to P-stress in Prochlorococcus. Environ Microbiol. 2013;15:2129-43.

97. Hommes RW, van Hell B, Postma PW, Neijssel OM, Tempest DW. The functional significance of glucose dehydrogenase in Klebsiella aerogenes. Arch Microbiol. 1985;143:163-8.

98. Wagh J, Shah S, Bhandari P, Archana G, Kumar GN. Heterologous expression of pyrroloquinoline quinone (pqq) gene cluster confers mineral phosphate solubilization ability to Herbaspirillum seropedicae Z67. Appl Microbiol Biotechnol. 2014;98:5117-29.
99. Monds RD, Newell PD, Schwartzman JA, O'Toole GA. Conservation of the Pho regulon in Pseudomonas fluorescens Pf0-1. Appl Environ Microbiol. 2006;72:1910-24.

100. Hopkinson BM, Dupont CL, Allen AE, Morel FMM. Efficiency of the $\mathrm{CO}_{2}$-concentrating mechanism of diatoms. Proc Natl Acad Sci. $2011 ; 108: 3830$.

101. Rosenberg H, Gerdes RG, Chegwidden K. Two systems for the uptake of phosphate in Escherichia coli. J Bacteriol. 1977; 131:505-11.

102. Scanlan DJ, Silman NJ, Donald KM, Wilson WH, Carr NG, Joint I, et al. An immunological approach to detect phosphate stress in populations and single cells of photosynthetic picoplankton. Appl Environ Microbiol. 1997;63:2411-20.

103. Lu J, Zhu B, Struewing I, Xu N, Duan S. Nitrogen-phosphorusassociated metabolic activities during the development of a cyanobacterial bloom revealed by metatranscriptomics. Sci Rep. 2019;9:1-11.

104. Wanner BL Phosphorus assimilation and its control of gene expression in Escherichia coli. In: Hauska G, Thauer RK (eds). Mol. Basis Bact. Metab. 1990. Springer, Berlin, Heidelberg, pp 152-63.

105. Pitt FD, Mazard S, Humphreys L, Scanlan DJ. Functional characterization of Synechocystis sp. strain PCC 6803 pst 1 and pst 2 gene clusters reveals a novel strategy for phosphate uptake in a freshwater cyanobacterium. J Bacteriol. 2010;192: 3512-23.

106. Hudek L, Premachandra D, Webster WAJ, Bräu L. Role of phosphate transport system component pstB1 in phosphate internalization by Nostoc punctiforme. Appl Environ Microbiol. 2016;82:6344-56.

107. Monds RD, Silby MW, Mahanty HK. Expression of the Pho regulon negatively regulates biofilm formation by Pseudomonas aureofaciens PA147-2. Mol Microbiol. 2001;42:415-26. 